\title{
Cerebral near-infrared spectroscopy insensitively detects low cerebral venous oxygen saturations after stage 1 palliation
}

\author{
Erin Rescoe, MD, ${ }^{\mathrm{a}, \mathrm{c}}$ Xiaoqi Tang, MA, ${ }^{\mathrm{a}}$ Dorothy Alison Perry, MBChB, ${ }^{\mathrm{a}, \mathrm{c}}$ Lynn A. Sleeper, ScD, ${ }^{\mathrm{a}, \mathrm{c}}$ \\ James A. DiNardo, MD, ${ }^{\text {b,d }}$ Barry D. Kussman, MBBCh, FFA(SA), ${ }^{\text {,d }}$ and John N. Kheir, MD ${ }^{\mathrm{a}, \mathrm{c}}$
}

\begin{abstract}
Background: Measurement of cerebral venous oxyhemoglobin saturation $\left(\mathrm{ScvO}_{2}\right)$ is considered a gold standard in assessing the adequacy of tissue oxygen delivery $\left(\mathrm{DO}_{2}\right)$ after the stage 1 palliation $(\mathrm{S} 1 \mathrm{P})$, with $\mathrm{SvO}_{2}<30 \%$ often representing severely compromised $\mathrm{DO}_{2}$. Regional oxygenation index $\left(\mathrm{rSO}_{2}\right)$ based on near-infrared resonance spectroscopy (NIRS) frequently is used to screen for compromised $\mathrm{DO}_{2}$, although its sensitivity to detect severe abnormalities in $\mathrm{SvO}_{2}$ is uncertain.
\end{abstract}

Methods: $\mathrm{ScvO}_{2}$ was measured by co-oximetry from the internal jugular vein as clinically indicated in 73 neonates after S1P. These values were compared with cerebral $\mathrm{rSO}_{2}$ (FORE-SIGHT; CASMED) via mixed effects model linear regression, Bland-Altman analysis, and sensitivity analysis. Because NIRS devices measure a composite of arterial and venous blood, we calculated an $\mathrm{rSO}_{2}$-based $\mathrm{ScvO}_{2}$ designed to remove arterial contamination from the $\mathrm{rSO}_{2}$ signal: $\mathrm{rSO}_{2}-$ based $\mathrm{ScvO}_{2}=\left(\mathrm{rSO}_{2}-\right.$ arterial oxygen saturation $\left.\times 0.3\right) / 0.7$.

Results: Among 520 time-matched pairs of $\mathrm{ScvO}_{2}$ and cerebral $\mathrm{rSO}_{2}$, the slope of the relationship between $\mathrm{rSO}_{2}$ and $\mathrm{ScvO}_{2}$ (after we adjusted for effects of hemoglobin) was $0.37 \pm 0.04$ with only modest correlation $\left(r^{2}=0.39\right)$, and mean bias of +8.26 . When $\mathrm{ScvO}_{2}$ was $<30 \%$, cerebral $\mathrm{rSO}_{2}$ was $<30$ in less than $1 \%,<40$ less than $1 \%$, and $<50$ in $45.7 \%$ of data points; specificity of $\mathrm{rSO}_{2}$ in the same range is $>99 \%$. Correction of $\mathrm{rSO}_{2}$ for arterial contamination significantly decreased mean bias $(+3.03)$ and improved the sensitivity of $\mathrm{rSO}_{2}$ to detect $\mathrm{ScvO}_{2}<30$ to $6.5 \%$ for $\mathrm{rSO}_{2}<30,29 \%$ for $\mathrm{rSO}_{2}<40$, and $77.4 \%$ for $\mathrm{rSO}_{2}<50$.

Conclusions: Cerebral $\mathrm{rSO}_{2}$ in isolation should not be used to detect low $\mathrm{ScvO}_{2}$, because its sensitivity is low, although correction of $\mathrm{rSO}_{2}$ for arterial contamination may improve sensitivity. Cerebral $\mathrm{rSO}_{2}$ of 50 or greater should not be considered reassuring, though values below 30 are specific for low $\mathrm{ScvO}_{2}$. (J Thorac Cardiovasc Surg 2017;154:1056-62)

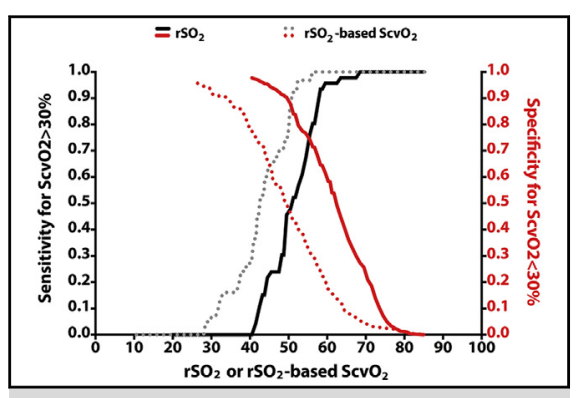

Sensitivity of near-infrared resonance spectroscopy for venous oxyhemoglobin saturation $<30 \%$ is low after stage 1 palliation.

\section{Central Message}

Cerebral near-infrared resonance spectroscopy (regional oxygenation saturation $\left[\mathrm{rSO}_{2}\right]$ ) insensitively detects cerebral venous oxyhemoglobin saturation less than $30 \%$ in the range of clinical interest (ie, $\mathrm{rSO}_{2}$ 30-50), a problem improved by correcting for arterial contamination ( $\mathrm{rSO}_{2}$-based cerebral venous oxyhemoglobin saturation).

\section{Perspective}

Although cerebral near-infrared resonance spectroscopy (regional oxygenation saturation) is commonly used to detect low cardiac output, the sensitivity of cerebral near-infrared resonance spectroscopy to detect venous oxyhemoglobin saturation less than $30 \%$ is low in the range of clinical interest after stage 1 palliation. This problem is ameliorated by correction of the signal for arterial contamination by backcalculating venous oxyhemoglobin saturation from regional oxygenation saturation and arterial oxygen saturation.

See Editorial Commentary page 1063.

See Editorial page 1054.
From the Departments of ${ }^{\mathrm{a} C}$ Cardiology and ${ }^{\mathrm{b}}$ Anesthesiology, Perioperative, and Pain Medicine, Boston Children's Hospital, and the Departments of 'Pediatrics and ${ }^{\mathrm{d}}$ Anaesthesia, Harvard Medical School, Boston, Mass.

Supported by the Gerber Foundation, Hess Family Philanthropic Fund, and the Boston Children's Hospital Heart Center Strategic Investment Fund.

Received for publication Sept 2, 2016; revisions received Jan 20, 2017; accepted for publication March 16, 2017; available ahead of print June 7, 2017.

\footnotetext{
Address for reprints: John N. Kheir, MD, Department of Cardiology, Boston Children's Hospital, 300 Longwood Ave, Boston, MA 02115 (E-mail: john.kheir@ childrens.harvard.edu). $0022-5223 / \$ 36.00$

Copyright (c) 2017 by The American Association for Thoracic Surgery http://dx.doi.org/10.1016/j.jtcvs.2017.03.154
} 


\section{Abbreviations and Acronyms \\ $\mathrm{DO}_{2}=$ systemic oxygen delivery \\ NIRS $=$ near-infrared resonance spectroscopy \\ $\mathrm{r}^{2}=$ correlation coefficient \\ $\mathrm{rSO}_{2}=$ regional oxygenation saturation \\ $\mathrm{S} 1 \mathrm{P}=$ stage 1 palliation \\ $\mathrm{SaO}_{2}=$ arterial oxygen saturation \\ $\mathrm{ScvO}_{2}=$ cerebral venous oxyhemoglobin saturation \\ $\mathrm{SvO}_{2}=$ venous oxyhemoglobin saturation}

\section{Scanning this QR code will take you to a supplemental video for the article.}

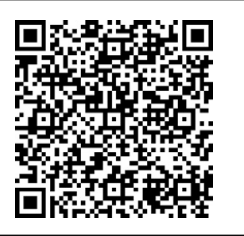

Optimization of systemic oxygen delivery $\left(\mathrm{DO}_{2}\right)$ during the early postoperative period after stage 1 palliation $(\mathrm{S} 1 \mathrm{P})$ requires accurate assessment of venous oxyhemoglobin saturation $\left(\mathrm{SvO}_{2}\right)$. Although true mixed venous blood sampling is anatomically precluded in single-ventricle anatomy, sampling from the superior vena cava (ie, cerebral venous oxyhemoglobin saturation, $\mathrm{ScvO}_{2}$ ) frequently is used as a representation of the adequacy of $\mathrm{DO}_{2}$ after S1P. ${ }^{1}$ When oxygen consumption exceeds $\mathrm{DO}_{2}$, tissue hypoxia develops, which increases oxygen dissociation from hemoglobin and causes venous oxyhemoglobin desaturation. In the single-ventricle population, it has been suggested that $\mathrm{ScvO}_{2}<30 \%$ represents the anaerobic threshold ${ }^{2}$ and that maintaining $\mathrm{ScvO}_{2}>50 \%$ in the early postoperative period is associated with improved survival. ${ }^{1,3,4}$ Thus, accurate assessment of $\mathrm{ScvO}_{2}$ after $\mathrm{S1P}$ is vital to the postoperative management of these patients.

Some groups have used venous oximetric catheters to permit continuous monitoring. ${ }^{5}$ These catheters are somewhat larger in caliber than standard catheters, may be more challenging to insert, and exhibit significant drift in calibration during use, such that their use is not widespread. Thus, a mainstay of patient monitoring is the use of surface oximetry with near-infrared spectroscopy (NIRS) to measure tissue $\mathrm{O}_{2}$ saturation. Cerebral oximetry is a noninvasive optical technology that relies on the relative transparency of biological tissues (eg, scalp and skull) to near-infrared light to measure brain oxygen saturation in an uncertain mixture of arterioles, capillaries, and venules. Commercial cerebral oximeters use continuous-wave, spatially resolved spectroscopy to measure the ratio of oxyhemoglobin to total hemoglobin, providing a cerebral hemoglobin oxygen saturation. The unit is percent $(\%)$ and is referred variably to as regional oxygen saturation $\left(\mathrm{rSO}_{2}\right)$, tissue oxygen saturation, or tissue oxygenation index, depending on the manufacturer. The ratio of venous to arterial blood in the sampled volume is approximately $70 \%$ to $30 \%,{ }^{6}$ although it can vary significantly (as much as $85 \% / 15 \%$ ). ${ }^{7}$ Although hemoglobin is distributed unevenly within arteries, arterioles, capillaries, venules, and veins, the venous to arterial ratio is estimated and fixed during the calibration and validation of the monitor (eg, $70 \%-75 \%$ venous $/ 25 \%-30 \%$ arterial $^{8-10}$ ). Because NIRS is used commonly as a noninvasive screening tool for inadequate $\mathrm{DO}_{2}$ after $\mathrm{S} 1 \mathrm{P}$, we examined the sensitivity and specificity of NIRS to detect low $\mathrm{ScvO}_{2}$ in the postoperative setting.

\section{METHODS \\ Patients}

The following retrospective study was approved by the Institutional Review Board at Boston Children's Hospital. We retrospectively studied 84 consecutive patients undergoing single-ventricle palliation for hypoplastic left heart syndrome at our institution between January 2013 and May 2016. Cerebral $\mathrm{rSO}_{2}$ (applied to the forehead without a preference or laterality) was measured as a part of routine clinical care during this period (FORE-SIGHT tissue oximeter; CASMED, Branford, Conn). Patients who did not have cerebral NIRS data recorded during the postoperative period $(n=3)$ were excluded from the study. During this period, placement of an internal jugular vein catheter with the tip in the proximal superior vena cava (at or above the junction with the right atrium) was also part of routine clinical practice. Blood sampled from the superior vena cava was analyzed routinely by co-oximetry in the hospital's core laboratory (Radiometer ABL 800; Radiometer America, Brea, Calif). Presence and position of the tip of the internal jugular catheter on the first chest radiograph after admission to the intensive care unit was assessed by 2 independent investigators (E.R. and J.K.). Data were excluded for patients in whom the tip of the catheter was deep within the right atrium $(n=8)$, leaving a total of 73 patients. Data also were excluded during the times that patients were on extracorporeal membrane oxygenation support. A total of 15,336 hours of patient monitoring were assessed.

\section{Data Extraction and Processing}

$\mathrm{ScvO}_{2}$ and hemoglobin were extracted automatically (Boston Children's Hospital 360; MicroStrategy, Inc, Tysons Corner, Va) from the hospital database in time- and patient-stamped fashion. Similarly, $\mathrm{rSO}_{2}$ was extracted from 1 of 2 sources. In a subset of patients $(n=20,26.3 \%)$, the NIRS device was tethered to the bedside monitor and the data continuously (ie, every 5 seconds) stored in a database and subsequently exported (T3 Data Collection and Analytics Software System; Etiometry, Inc, Boston, Mass) and down-sampled to every 5-minute median values (MatLab, R2015b, 8.6; MathWorks Inc, Natick, Mass). In the remainder, NIRS data were entered manually by the bedside nurse at least twice per shift, and these data were extracted from the hospital database as described previously. All data were normalized to elapsed time after removal of the aortic crossclamp (the final was chosen if multiple) via a customized MatLab script.

\section{Data Analyses}

Time-matched $\mathrm{rSO}_{2}$ measurements were compared with $\mathrm{ScvO}_{2}$ measurements with the use of several techniques. First, the partial correlation coefficient and slope of the relationship were measured with mixedeffects model linear regression to account for repeated measures and to control for hemoglobin with $\mathrm{ScvO}_{2}$ as the outcome. Second, the mean bias and standard deviation (limits of agreement) between the 2 measurements were compared by Bland-Altman analysis corrected for replicate 
TABLE 1. Preoperative and operative characteristics of patients included in the study

\begin{tabular}{lr}
\hline \multicolumn{1}{c}{ Variables } & Mean \pm SD \\
\hline Preoperative variables & \\
$\quad$ Age at surgery, $\mathrm{d}$ & $7.9 \pm 15.2$ \\
$\quad$ Birth weight, $\mathrm{kg}$ & $3.15 \pm 0.48$ \\
Shunt type & \\
$\quad$ Sano conduit & $57(78 \%)$ \\
$\quad$ Modified Blalock-Taussig shunt & $16(22 \%)$ \\
Bypass times, min & \\
Cardiopulmonary bypass time & $173 \pm 46$ \\
$\quad$ Aortic crossclamp time & $98 \pm 37$ \\
RLFP time & $71 \pm 23$ \\
Circulatory arrest time & $21 \pm 19$ \\
\hline$S D$, Standard deviation; $R L F P$, regional low flow perfusion.
\end{tabular}

measurements. ${ }^{11}$ Third, the sensitivity and specificity of NIRS to detect $\mathrm{ScvO}_{2}$ critical thresholds were assessed with receiver operating characteristic analysis by defining the presence of deficient oxygen delivery (ie, disease present) as $\mathrm{ScvO}_{2}<30 \%,<40 \%$, or $<50 \%$. Sensitivity and specificity curves were then created to describe the $\mathrm{rSO}_{2}$ values at which NIRS is sufficiently sensitive to detect $\mathrm{ScvO}_{2}<30 \%$.

\section{Calculation of $\mathrm{rSO}_{2}$-based $\mathrm{ScvO}_{2}$}

Because the FORE-SIGHT device is calibrated based on a $30 \%$ arterial to $70 \%$ venous ratio, ${ }^{7,8}$ we calculated an $\mathrm{rSO}_{2}$-based $\mathrm{ScvO}_{2}$ using $\mathrm{rSO}_{2}$ and arterial oxygen saturation $\left(\mathrm{SaO}_{2}\right.$; exported in similar fashion to $\mathrm{SvO}_{2}$ as described previously) according to the following equation ${ }^{12}: \mathrm{rSO}_{2}$-based $\mathrm{ScvO}_{2}=\left(\mathrm{rSO}_{2}-\mathrm{SaO}_{2} * 0.3\right) / 0.7$. Completion of this calculation requires simultaneous estimation of $\mathrm{SaO}_{2}, \mathrm{ScvO}_{2}$, and $\mathrm{rSO}_{2}$. To permit this exploratory evaluation, we interpolated all values for these 3 variables over time to provide a "best guess" for each value at 5-minute intervals. This process assumed that the rate of change between each intermittently measured value was linear. For example, if $\mathrm{ScvO}_{2}$ at hour 1 was $50 \%$ and at hour 2 was $60 \%, \mathrm{ScvO}_{2}$ at 90 minutes was assumed to have been $55 \%$. $\mathrm{rSO}_{2}$-based $\mathrm{ScvO}_{2}$ was then compared with $\mathrm{ScvO}_{2}$ via the same techniques as described previously for $\mathrm{rSO}_{2}$ and $\mathrm{ScvO}_{2}$.

\section{Evaluation of $\mathrm{rSO}_{2}$ as a Trend Monitor}

Because NIRS frequently is considered an effective trend monitor, we examined changes in $\mathrm{rSO}_{2}$ with changes in $\mathrm{ScvO}_{2}$ using the interpolated dataset described previously. Change in $\mathrm{rSO}_{2}$ and change in $\mathrm{ScvO}_{2}$ were calculated at hourly intervals and compared with one another. Data points in which there was a less than $\pm 5 \%$ change in both $\mathrm{ScvO}_{2}$ and $\mathrm{rSO}_{2}$ were excluded. The proportion of data points in which both $\mathrm{rSO}_{2}$ and $\mathrm{ScvO}_{2}$ changed in the same or opposite directions by more than $5 \%$ (empirically chosen as a potentially significant change) were described, as was the proportion in which $\mathrm{rSO}_{2}$ or $\mathrm{ScvO}_{2}$ changed without a corresponding change in the other test. Data were described as percentages of total data points.

\section{RESULTS}

Demographic and Surgical Variables

The demographic and surgical information regarding shunt types and operative times is described in Table 1. The majority of shunt types during the study period were Sano conduits.

\section{Relationship Between $\mathrm{rSO}_{2}$ and $\mathrm{ScvO}_{2}$}

Among $3539 \mathrm{ScvO}_{2}$ measurements, a time-matched $\mathrm{rSO}_{2}$ was found in 520 instances. Notably, in all results in which
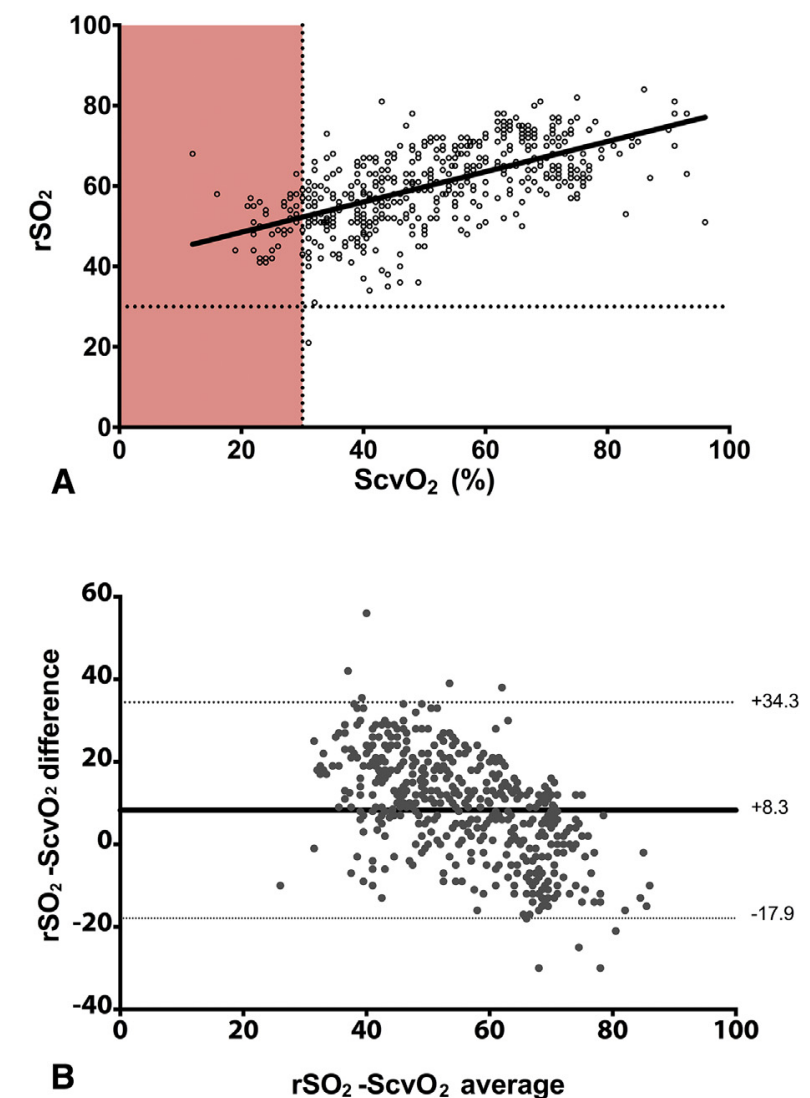

FIGURE 1. A, Raw data for $\mathrm{rSO}_{2}$ and $\mathrm{ScvO}_{2}$ with crude linear regression line. Among all $\mathrm{ScvO}_{2}<30$, there were no $\mathrm{rSO}_{2}$ values $<30$. B, BlandAltman analysis of $\mathrm{rSO}_{2}$ relative to $\mathrm{ScvO}_{2}$ demonstrated a mean bias of +8.3 (limits of agreement +34.3 to -17.9 ). $r \mathrm{SO}_{2}$, Regional oxygenation index; $\mathrm{Scv}_{2}$, cerebral venous oxyhemoglobin saturation.

$\mathrm{ScvO}_{2}$ was $<30 \%, \mathrm{rSO}_{2}$ was $>30$ (Figure $1, A$ ). Even with adjustment for effects of time and hemoglobin concentration, we found $\mathrm{rSO}_{2}$ to be an independent predictor of $\mathrm{ScvO}_{2}$ (partial $\mathrm{r}^{2}=0.39, P<.0001$ ); for every 1-unit increase in $\mathrm{rSO}_{2}$ there is on average a $0.37 \pm 0.04$ unit $(\%$ point) increase in $\mathrm{ScvO}_{2}$. The mean bias of $\mathrm{rSO}_{2}$ compared with $\mathrm{ScvO}_{2}$ was +8.26 with a standard deviation of 13.1 (Figure 1, B).

Sensitivity and Specificity of $\mathrm{rSO}_{2}$ for $\mathrm{ScvO}_{2}<30 \%$

Using the same time-matched pairs of $\mathrm{rSO}_{2}$ and $\mathrm{ScvO}_{2}$, we found that the area under receiver operating characteristics curves for $\mathrm{rSO}_{2}$ as a diagnostic test to detect $\mathrm{ScvO}_{2}$ $<30 \%,<40 \%$, and $<50 \%$ were $0.82,0.84$, and 0.87 , respectively (Figure 2, A). However, the sensitivity of $\mathrm{rSO}_{2}$ in the range of clinical interest in detecting $\mathrm{ScvO}_{2}<30 \%$ is extremely low. As shown in Figure 2, B, $\mathrm{rSO}_{2}$ is $<30$ less than $1 \%$ of the time that $\mathrm{ScvO}_{2}$ is $<30 \%, \mathrm{rSO}_{2}<40$ less than $1 \%$ of the time, and $<50$ only $45.7 \%$ of the time that $\mathrm{ScvO}_{2}$ is $<30 \%$. Conversely, the specificity of $\mathrm{rSO}_{2}$ is favorable; $\mathrm{rSO}_{2}<30$ indicates that $\mathrm{ScvO}_{2}$ will be $<30 \%$ more than $99 \%$ of the time. As is 

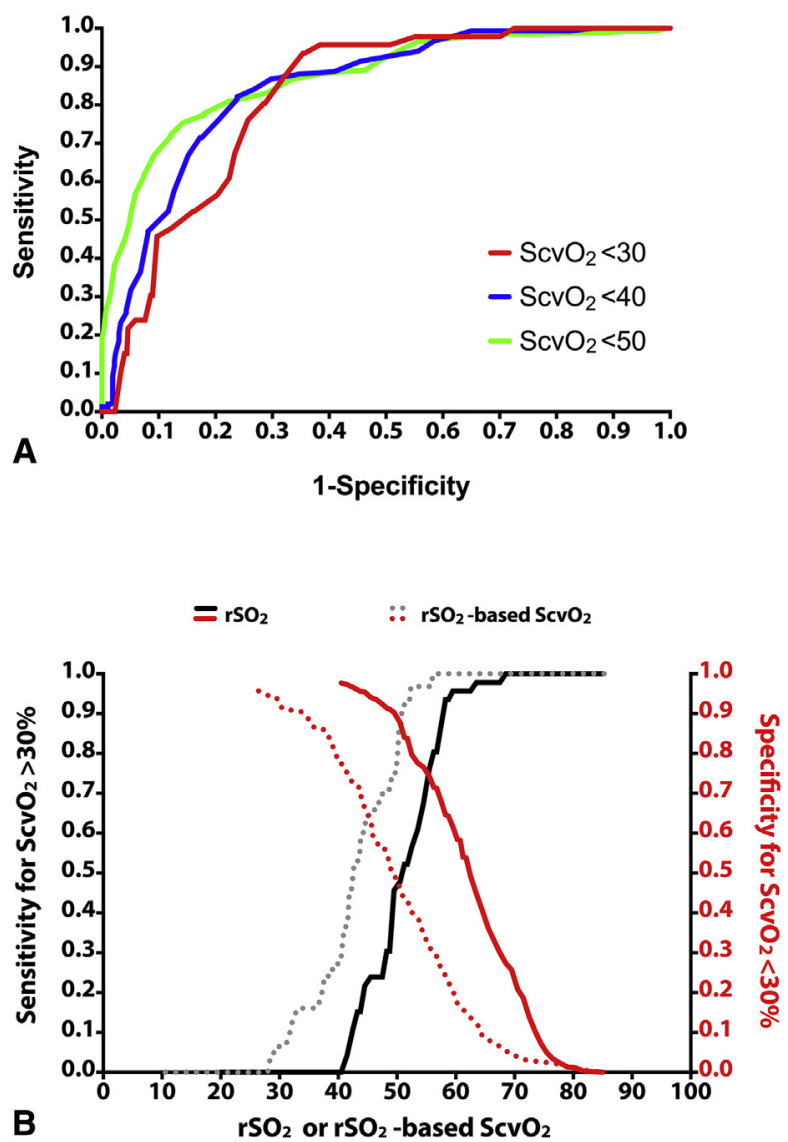

FIGURE 2. A, Receiver operating characteristics curve analysis of $\mathrm{rSO}_{2}$ to detect $\mathrm{ScvO}_{2}<30 \%$ (red line, AUC 0.82, optimal cutoff point $\mathrm{rSO}_{2}$ 58.3 ), $\mathrm{ScvO}_{2}<40 \%$ (blue line, AUC 0.84, optimal cutoff point $\mathrm{rSO}_{2}$ 58.8 ), and $\mathrm{ScvO}_{2}<50 \%$ (green line, AUC 0.87, optimal cutoff point $\mathrm{rSO}_{2}$ 59.5). B, Defining $\mathrm{ScvO}_{2}<30 \%$ as the presence of disease, $\mathrm{rSO}_{2}$ (black line) was $<30$ in $<1 \%$ of data points, $<40$ in $<1 \%$ of data points, and $<50$ in $45.7 \%$ of data points. Subtracting arterial contamination (ie, $\mathrm{rSO}_{2}$-based $\mathrm{ScvO}_{2}$, gray dotted line) improved sensitivity significantly: when $\mathrm{ScvO}_{2}<30, \mathrm{rSO}_{2}$-based $\mathrm{ScvO}_{2}$ was $<30$ in $6.5 \%$ of data points, $<40$ in $29 \%$ of data points, and $<50$ in $77.4 \%$ of data points. The specificity of $\mathrm{rSO}_{2}$ (solid red line) for $\mathrm{ScvO}_{2}<30 \%$ decreased from $97 \%$ at $\mathrm{rSO}_{2}$ of 40 to $88 \%$ at $\mathrm{rSO}_{2}$ of 50 . Subtracting arterial contamination (ie, $\mathrm{rSO}_{2}$-based $\mathrm{ScvO}_{2}$, red dotted line) decreased the specificity to in $81 \%$ at $\mathrm{rSO}_{2}$ of 40 and $46 \%$ at $\mathrm{rSO}_{2}$ of $50 . \mathrm{ScvO}_{2}$, Cerebral venous oxyhemoglobin saturation; $\mathrm{rSO}_{2}$, regional oxygenation index.

the case with many diagnostic tests, the choice of threshold values represents a compromise between sensitivity and specificity. Some authors have suggested addressing this problem through a "gray zone" approach in which 2 (in this case, $\mathrm{rSO}_{2}$ ) cutoffs are set: the first cutoff is chosen to exclude the diagnosis (here, $\mathrm{ScvO}_{2}<30 \%$ ) with nearcertainty (ie, privilege specificity) and the second cutoff is chosen to include the diagnosis with near-certainty (ie, privilege sensitivity). ${ }^{13}$ In this case, the gray zone would be between an $\mathrm{rSO}_{2}$ value of 49 (affording a privilege specificity of $90 \%$ ) and 58 (affording a privilege sensitivity of $90 \%$ ), which overlaps the expected range of $\mathrm{rSO}_{2}$ completely.

\section{$\mathrm{rSO}_{2}$-based $\mathrm{ScvO}_{2}$ Calculations}

We identified $3539 \mathrm{ScvO}_{2}$ values, $3084 \mathrm{SaO}_{2}$ values, and $28,836 \mathrm{rSO}_{2}$ values among the 73 patients examined. Interpolation of these data over time permitted the comparison of 94,739 time-matched data points of $\mathrm{rSO}_{2}$ and $\mathrm{ScvO}_{2}$ (every 5 minutes). As expected, correcting $\mathrm{rSO}_{2}$ for arterial contamination (by back-calculating $\mathrm{ScvO}_{2}$ based on $\mathrm{rSO}_{2}$ ) increased the slope of the $\mathrm{rSO}_{2}$-based $\mathrm{ScvO}_{2}$ estimate relative to time-matched $\mathrm{ScvO}_{2}$ (from 0.38 to 0.41). The mean bias of $\mathrm{rSO}_{2}$-based $\mathrm{ScvO}_{2}$ relative to $\mathrm{ScvO}_{2}$ was 3.03. Correction for arterial contamination improved the sensitivity of $\mathrm{rSO}_{2}$ to detect $\mathrm{ScvO}_{2}<30$ to $6.5 \%$ for $\mathrm{rSO}_{2}<30$, $29.0 \%$ for $\mathrm{rSO}_{2}<40$, and $77.4 \%$ for $\mathrm{rSO}_{2}<50$ (Figure 2, $B$, gray dotted line). Even with adjustment for effects of time and hemoglobin concentration, we found $\mathrm{rSO}_{2}$-based $\mathrm{ScvO}_{2}$ to be an independent predictor of $\mathrm{ScvO}_{2}$ (partial $\left.\mathrm{r}^{2}=0.42, P<.0001\right)$; for every 1 -unit increase in $\mathrm{rSO}_{2-}$ based $\mathrm{ScvO}_{2}$ there is on average a $0.58 \pm 0.08$ unit $(\%$ point) increase in $\mathrm{ScvO}_{2}$.

\section{Use of $\mathrm{rSO}_{2}$ to Trend $\mathrm{ScvO}_{2}$}

We calculated 7834 time-matched hourly changes in $\mathrm{rSO}_{2}$ and $\mathrm{ScvO}_{2}$. Of these, there were $7242(92.4 \%)$ changes in which both the $\mathrm{rSO}_{2}$ and $\mathrm{ScvO}_{2}$ changed $<5 \%$. Excluding these "minimal change values," $\sim 70 \%$ of data points were characterized by a $>5 \%$ change in $\mathrm{rSO}_{2}$ with a minimal change in $\mathrm{ScvO}_{2}$ and $\sim 25 \%$ by a significant ( $>5 \%$ ) change in $\mathrm{ScvO}_{2}$ with minimal $\left(<5 \%\right.$ ) change in $\mathrm{rSO}_{2}$ (Figure 3). A minority $(5 \%)$ of data points exhibited significant changes in $\mathrm{rSO}_{2}$ and $\mathrm{ScvO}_{2}$ in the same direction.

\section{DISCUSSION}

Although the primary purpose of NIRS monitoring is to permit the early detection of venous desaturation, we found that cerebral $\mathrm{rSO}_{2}$ in isolation is highly insensitive but very specific for venous hypoxia in newborns after S1P. The area under the curve for cerebral $\mathrm{rSO}_{2}$ was high for a diagnostic test, although this finding did not reflect the extremely poor utility of the test as a screening tool for $\mathrm{ScvO}_{2}<30 \%$. In our cohort, patients with $\mathrm{ScvO}_{2}<30 \%$ exhibited a cerebral $\mathrm{rSO}_{2}<30$ less than $1 \%$ of the time (ie, sensitivity), and $\mathrm{rSO}_{2}<50$ only $46 \%$ of the time. Correction of the $\mathrm{rSO}_{2}$ signal for the $30 \% \mathrm{SaO}_{2}$ component decreased the mean bias relative to $\mathrm{ScvO}_{2}$, but the sensitivity remained extremely poor in the range of clinical interest. Regarding $\mathrm{ScvO}_{2}$, a "reassuring" cerebral NIRS (eg, $\mathrm{rSO}_{2}>50$ ) should not be considered reassuring in isolation, and an $\mathrm{rSO}_{2}<40 \%$ should be concerning.

There is compelling evidence that NIRS values in the operating room correlate with clinical outcomes. Operative monitoring during cardiopulmonary bypass is now a routine part of monitoring, and with good reason. Low cerebral NIRS values have been correlated with an increased 


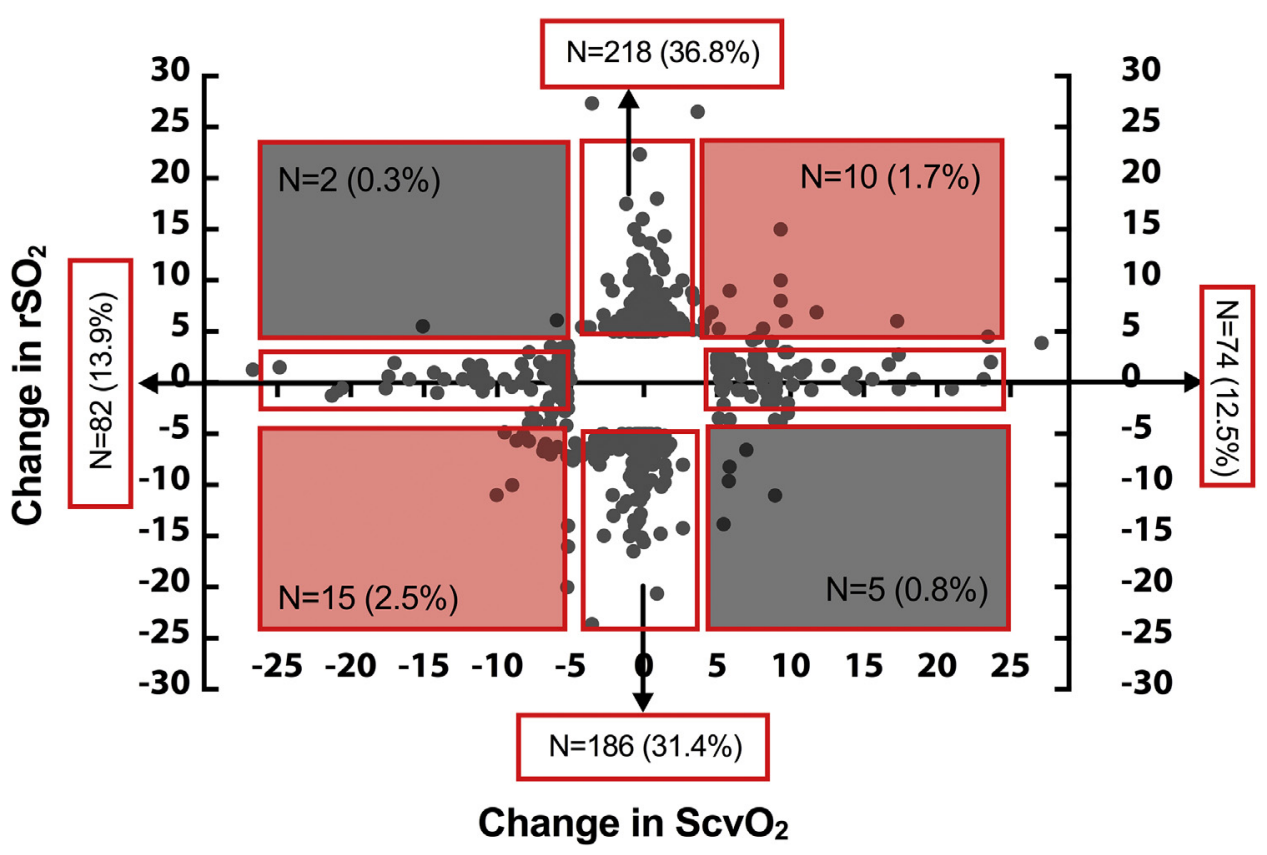

FIGURE 3. Among the 7834 hourly matched $\mathrm{rSO}_{2}-\mathrm{ScvO}_{2}$ pairs, the majority $(7242 ; 92.4 \%)$ of pairs were characterized by $<5 \%$ change in both $\mathrm{rSO}_{2}$ and $\mathrm{ScvO}_{2}$. Excluding these "minimal change values," there were more values characterized by a significant change in $\mathrm{rSO}_{2}$ with a minimal change $(<5 \%)$ in $\mathrm{ScvO}_{2}(404 ; 68.2 \%)$ than were characterized by a significant change in $\mathrm{ScvO}_{2}$ with minimal change in $\mathrm{rSO}_{2}(156,26.3 \%, P<.0001, \mathrm{McNemar}$ test). A minority of data points exhibited significant changes in both $\mathrm{rSO}_{2}$ and $\mathrm{ScvO}_{2}$ in the same direction (shaded red, $5 \%$ ) or in opposite directions (shaded black, $1.1 \%$ ). $\mathrm{ScvO}_{2}$, Cerebral venous oxyhemoglobin saturation; $\mathrm{rSO}_{2}$, regional oxygenation index.

prevalence of radiographically apparent neurologic injury, ${ }^{14}$ increased biochemical markers of brain injury, ${ }^{15}$ and developmental maturity at 1 -year follow-up. ${ }^{16}$ It also has been suggested that preoperative cerebral NIRS values may correlate with neurodevelopmental outcome. ${ }^{17}$

In addition to its use in the operating room, however, NIRS frequently is used in the intensive care environment as a screening tool to identify deficient $\mathrm{DO}_{2}$ among biochemically and otherwise-reassuring patients. Thus, a clear understanding of its correlation with $\mathrm{ScvO}_{2}$ is paramount to its proper interpretation. Specifically, because it is clear that $\mathrm{ScvO}_{2}<30 \%$ is associated with poor outcomes, ${ }^{2,18}$ the sensitivity and specificity of NIRS to detect this extreme physiologic state is important to quantify. The strength of correlation between cerebral $\mathrm{rSO}_{2}$ and $\mathrm{ScvO}_{2}$ has been described several times, often in the catheterization laboratory setting, and is highly variable, ranging from $\sim 0.3^{19}$ to (less commonly) $\sim 0.9 .{ }^{20}$ The slope of the relationship between $\mathrm{rSO}_{2}$ and $\mathrm{ScvO}_{2}$ has been reported repeatedly to be less than 0.5 , indicating that $\mathrm{rSO}_{2}$ reproducibly overestimates $\mathrm{ScvO}_{2}$ with a mean bias in the $+5 \%$ to $10 \%$ (ie, cerebral $\mathrm{rSO}_{2}>\mathrm{ScvO}_{2}$ ) range. ${ }^{19,21-23}$ We found results similar to these and were surprised by the extremely low sensitivity of cerebral NIRS to detect even the most severe aberrations in $\mathrm{DO}_{2}$ (ie, $\mathrm{ScvO}_{2}<30 \%$ ). We also noted that cerebral $\mathrm{rSO}_{2}$ frequently changes in the absence of corresponding $\mathrm{ScvO}_{2}$ changes and conversely may not reflect measured $\mathrm{ScvO}_{2}$ changes. This phenomenon was also described in 70 infants after congenital heart surgery, in which cerebral $\mathrm{rSO}_{2}$ and $\mathrm{ScvO}_{2}$ changed in opposite directions $\sim 40 \%$ of the time. ${ }^{24}$ These findings raise concerns regarding the utility of cerebral NIRS even as a trend monitor, as shown in Video 1.

There are several possible explanations for the poor sensitivity, or systematic overestimation, of $\mathrm{rSO}_{2}$ relative to $\mathrm{ScvO}_{2}$ in our study. One of the important limitations of current NIRS technology is the use of a fixed ratio of venous to arterial blood volume distribution (eg, 30:70), an estimate that has not been validated for the cerebral circulation in vivo and may in fact be closer to $15: 85 .^{7}$ This is consistent with the substantially improved sensitivity of cerebral $\mathrm{rSO}_{2}$ in our study after correction of $\mathrm{rSO}_{2}$ for arterial contamination. Furthermore, it is likely that this ratio is dynamic in the perioperative period, given the variability in cardiac output, arterial, and venous pressures and capacitance, temperature, carbon dioxide and oxygen tensions, and vasoactive agent administration that is common after S1P. It is possible that the emergence of frequency domain NIRS will obviate the need to estimate the venous-arterial ratio and permit more sensitive identification of cerebral venous desaturation. ${ }^{25}$

Another explanation may be contamination of the region of interest with myoglobin, which shares similar optical properties to hemoglobin. Because of myoglobin's profound affinity for oxygen (oxygen tension at which hemoglobin is $50 \%$ saturated $\sim 3.5 \mathrm{~mm} \mathrm{Hg}$ ), myoglobin 


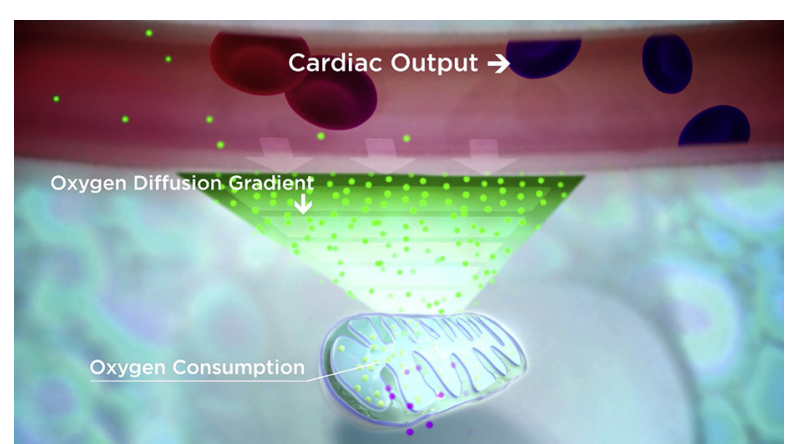

VIDEO 1. Cerebral oxygen delivery in the single-ventricle circulation can be compromised by diminished cardiac output, diminished systemic blood flow, arterial hypoxemia, anemia, and other causes. Accurate assessment of the adequacy of cerebral oxygen delivery is vital to the treatment of these patients. Because measurement of gold standards such as tissue oxygen tension and mixed venous saturation are precluded in infants with univentricular heart disease, adequacy of $\mathrm{DO}_{2}$ frequently is performed through oxyhemoglobin saturation of blood from the superior vena cava $\left(\mathrm{ScvO}_{2}\right)$. Because of the risks of repeated phlebotomy, cerebral NIRS is used commonly as a surrogate metric to screen patients for deficient $\mathrm{DO}_{2}$. In this study, we found that cerebral NIRS values are insensitive in detecting $\mathrm{ScvO}_{2}<30 \%$ until the $\mathrm{rSO}_{2}$ exceeds 50 , which is near the normal range. Mathematically subtracting the arterial component from $\mathrm{rSO}_{2}$ improved sensitivity for $\mathrm{ScvO}_{2}<30 \%$ significantly. In the intensive care unit, a cerebral $\mathrm{rSO}_{2}$ in the normal range should not be considered reassuring, at least in isolation. Video produced by Alexanimation, LLC. Video available at: http://www.jtcvsonline.org/article/S0022-5223(17)30900-5/addons.

remains in the oxygenated state in nearly all clinically relevant circumstances and may lead to a systematic overestimation of oxyhemoglobin concentration if the signal is not distinguished properly. However, this would not be expected to be a major contributor to transcranial readings in a newborn, given the diminutive muscle mass of the frontotemporal region. ${ }^{26}$ Furthermore, different iterations of devices from a variety of manufacturers may perform differently based on internal algorithms. ${ }^{27,28}$

It is important to note that $\mathrm{rSO}_{2}$ has been shown to be useful as a screening tool when somatic and cerebral $\mathrm{rSO}_{2}$ are used in combination. Specifically, the difference between somatic and cerebral $\mathrm{rSO}_{2}$ in healthy infants is known to be $\sim 10 \%$ (ie, renal-somatic $\mathrm{rSO}_{2}$ is $\sim 8-10$ greater than cerebral $\mathrm{rSO}_{2}{ }^{29}$ ), putatively reflecting the high ratio of oxygen delivery to oxygen demand of the kidneys (given their function as a blood filter) relative to that of the brain. Under conditions of redistribution (eg, shock states), however, the somatic-cerebral $\mathrm{rSO}_{2}$ difference is abolished or even reversed, reflecting the redistribution of limited blood flow toward the brain and away from the abdomen. It has even been suggested that a lower somatic-cerebral $\mathrm{rSO}_{2}$ difference correlates with length of stay, biochemical markers of malperfusion, and mortality after S1P. ${ }^{30}$ Thus, it is likely that use of cerebral and somatic NIRS in combination would improve sensitivity for low $\mathrm{ScvO}_{2}$; cerebral $\mathrm{rSO}_{2}$ in isolation performs poorly.

\section{Limitations}

There are several limitations to our study that merit discussion. Given that this was intended to be a study of the utility of NIRS as a reflection of clinically followed $\mathrm{ScvO}_{2}$, the $\mathrm{ScvO}_{2}$ was drawn from internal jugular catheters placed at the superior vena cava-right atrial junction, rather than within the jugular bulb. It is possible that the sensitivity of $\mathrm{rSO}_{2}$ would have improved if we had compared it with $\mathrm{SvO}_{2}$ from the jugular bulb. We were careful to only use $\mathrm{ScvO}_{2}$ from catheters terminating outside the bounds of the common atrium, although it is possible for venous samples to become arterialized by rapid sampling or by bubble contamination. However, these sources of error would raise $\mathrm{ScvO}_{2}$ measurements and diminish the biases we found. Second, we used a data interpolation scheme to accomplish data matching between $\mathrm{SaO}_{2}, \mathrm{ScvO}_{2}$, and $\mathrm{rSO}_{2}$ to remove arterial contamination from the $\mathrm{rSO}_{2}$ signal and to examine changes over time. This technique makes major assumptions regarding linear rates of change over time that may not be true. In the future, a prospective study with matched arterial and venous blood sampling may obviate the need for this technique.

\section{CONCLUSIONS}

Cerebral $\mathrm{rSO}_{2}$ in isolation should not be used to detect low $\mathrm{ScvO}_{2}$, because its sensitivity is low, although correction of $\mathrm{rSO}_{2}$ for arterial contamination significantly improves sensitivity. Cerebral $\mathrm{rSO}_{2}$ of 50 or greater should not be considered reassuring with regard to $\mathrm{ScvO}_{2}$, although values $<30$ are specific for low $\mathrm{ScvO}_{2}$.

\section{Conflict of Interest Statement}

Authors have nothing to disclose with regard to commercial support.

\section{References}

1. Tweddell JS, Ghanayem NS, Mussatto KA, Mitchell ME, Lamers LJ, Musa NL, et al. Mixed venous oxygen saturation monitoring after stage 1 palliation for hypoplastic left heart syndrome. Ann Thorac Surg. 2007;84:1301-11.

2. Hoffman GM, Ghanayem NS, Kampine JM, Berger S, Mussatto KA, Tweddell JS. Venous saturation and the anaerobic threshold in neonates after the Norwood procedure for hypoplastic left heart syndrome. Ann Thorac Surg. 2000;70:1515-20; discussion 1521.

3. Tweddell JS, Hoffman GM, Mussatto KA, Fedderly RT, Berger S, Jaquiss RD, et al. Improved survival of patients undergoing palliation of hypoplastic left heart syndrome: lessons learned from 115 consecutive patients. Circulation. 2002; 106(12 suppl 1):I82-9.

4. Hoffman GM, Tweddell JS, Ghanayem NS, Mussatto KA, Stuth EA, Jaquis RD, et al. Alteration of the critical arteriovenous oxygen saturation relationship by sustained afterload reduction after the Norwood procedure. J Thorac Cardiovasc Surg. 2004;127:738-45.

5. Tweddell JS, Hoffman GM, Fedderly RT, Berger S, Thomas JP Jr, Ghanayem NS, et al. Phenoxybenzamine improves systemic oxygen delivery after the Norwood procedure. Ann Thorac Surg. 1999;67:161-7; discussion 167-8.

6. Ito H, Kanno I, Iida H, Hatazawa J, Shimosegawa E, Tamura H, et al. Arterial fraction of cerebral blood volume in humans measured by positron emission tomography. Ann Nucl Med. 2001;15:111-6. 
7. Watzman HM, Kurth CD, Montenegro LM, Rome J, Steven JM, Nicolson SC Arterial and venous contributions to near-infrared cerebral oximetry. Anesthesiology. 2000;93:947-53.

8. Benni PB, Chen B, Dykes FD, Wagoner SF, Heard M, Tanner AJ, et al. Validation of the CAS neonatal NIRS system by monitoring vv-ECMO patients: preliminary results. Adv Exp Med Biol. 2005;566:195-201.

9. Pollard V, Prough DS, Demelo AE, Deyo DJ, Uchida T, Stoddart HF. Validation in volunteers of a near-infrared spectroscope for monitoring brain oxygenation in vivo. Anesth Analg. 1996;82:269-77.

10. McCormick PW, Stewart M, Goetting MG, Balakrishnan G. Regional cerebrovascular oxygen saturation measured by optical spectroscopy in humans. Stroke. 1991;22:596-602.

11. Carstensen B, Simpson J, Gurrin LC. Statistical models for assessing agreement in method comparison studies with replicate measurements. Int J Biostatist. 2008;4:1-28.

12. Ikeda K, MacLeod DB, Grocott HP, Moretti EW, Ames W, Vacchiano C. The accuracy of a near-infrared spectroscopy cerebral oximetry device and its potential value for estimating jugular venous oxygen saturation. Anesth Analg. 2014;119:1381-92.

13. Cannesson M, Le-Manach Y, Hofer CK, Goarin JP, Lehot JJ, Vallet B, et al. Assessing the diagnostic accuracy of pulse pressure variations for the prediction of fluid responsiveness: a "gray zone" approach. Anesthesiology. 2011;115:231-41.

14. Dent CL, Spaeth JP, Jones BV, Schwartz SM, Glauser TA, Hallinan B, et al. Brain magnetic resonance imaging abnormalities after the Norwood procedure using regional cerebral perfusion. J Thorac Cardiovasc Surg. 2006;131:190-7.

15. Abu-Sultaneh S, Hehir DA, Murkowski K, Ghanayem NS, Liedel J, Hoffmann RG, et al. Changes in cerebral oxygen saturation correlate with $\mathrm{S} 100 \mathrm{~B}$ in infants undergoing cardiac surgery with cardiopulmonary bypass. $P e$ diatr Crit Care Med. 2014;15:219-28.

16. Kussman BD, Wypij D, Laussen PC, Soul JS, Bellinger DC, DiNardo JA, et al Relationship of intraoperative cerebral oxygen saturation to neurodevelopmental outcome and brain magnetic resonance imaging at 1 year of age in infants undergoing biventricular repair. Circulation. 2010;122:245-54.

17. Hansen JH, Rotermann I, Logoteta J, Jung O, Dütschke P, Scheewe J, et al. Neurodevelopmental outcome in hypoplastic left heart syndrome: impact of perioperative cerebral tissue oxygenation of the Norwood procedure. J Thorac Cardiovasc Surg. 2016;151:1358-66.

18. Ronco JJ, Ronco JJ, Fenwick JC, Wiggs BR, Phang PT, Cooper DJ, et al. Identification of the critical oxygen delivery for anaerobic metabolism in critically ill septic and nonseptic humans. JAMA. 1993;270:1724-30.

19. Ricci Z, Garisto C, Favia I, Schloderer U, Giorni C, Fragasso T, et al. Cerebral NIRS as a marker of superior vena cava oxygen saturation in neonates with congenital heart disease. Paediatr Anaesth. 2010;20:1040-5.

20. Abdul-Khaliq H, Troitzsch D, Berger F, Lange PE. Regional transcranial oximetry with near infrared spectroscopy (NIRS) in comparison with measuring oxy- gen saturation in the jugular bulb in infants and children for monitoring cerebral oxygenation [in German]. Biomed Tech (Berl). 2000;45:328-32.

21. Nagdyman N, Ewert P, Peters B, MIERA O, Fleck T, Berger F. Comparison of different near-infrared spectroscopic cerebral oxygenation indices with central venous and jugular venous oxygenation saturation in children. Paediatr Anaesth. 2008; 18:160-6.

22. Li J, Van Arsdell GS, Zhang G, Cai S, Humpl T, Caldarone CA, et al. Assessment of the relationship between cerebral and splanchnic oxygen saturations measured by near-infrared spectroscopy and direct measurements of systemic haemodynamic variables and oxygen transport after the Norwood procedure. Heart. 2006;92:1678-85.

23. Tortoriello TA, Stayer SA, Mott AR, McKenzie ED, Fraser CD, Andropoulos DB, et al. A noninvasive estimation of mixed venous oxygen saturation using near-infrared spectroscopy by cerebral oximetry in pediatric cardiac surgery patients. Paediatr Anaesth. 2005;15:495-503.

24. McQuillen PS, Nishimoto MS, Bottrell CL, Fineman LD, Hamrick SE, Glidden DV, et al. Regional and central venous oxygen saturation monitoring following pediatric cardiac surgery: Concordance and association with clinical variables. Pediatr Crit Care Med. 2007;8:154-60.

25. Dehaes M, Aggarwal A, Lin P-Y, Rosa Fortuno C, Fenoglio A, Roche-Labarbe N, et al. Cerebral oxygen metabolism in neonatal hypoxic ischemic encephalopathy during and after therapeutic hypothermia. J Cereb Blood Flow Metab. 2014;34 $87-94$.

26. Scheeren TWL, Schober P, Schwarte LA. Monitoring tissue oxygenation by near infrared spectroscopy (NIRS): background and current applications. J Clin Monit Comput. 2012;26:279-87.

27. Naguib AN, Winch PD, Sebastian R, Gomez D, Guzman L, Rice J, et al. The correlation of two cerebral saturation monitors with jugular bulb oxygen saturation in children undergoing cardiopulmonary bypass for congenital heart surgery. J Intensive Care Med. August 15, 2016 [Epub ahead of print].

28. Bickler PE, Feiner JR, Rollins MD. Factors affecting the performance of 5 cerebral oximeters during hypoxia in healthy volunteers. Anesth Analg. 2013;117: 813-23.

29. Bernal NP, Hoffman GM, Ghanayem NS, Arca MJ. Cerebral and somatic nearinfrared spectroscopy in normal newborns. J Pediatr Surg. 2010;45:1306-10.

30. Hoffman GM, Ghanayem NS, Mussatto KA, Berens RJ, Tweddell JS. Postoperative two-site NIRS predicts complications and mortality after stage 1 palliation of HLHS. Anesthesiology. 2007;107:A234.

Key Words: Norwood procedure, near-infrared spectroscopy, oxygen delivery, hypoxemia, postoperative monitoring

Readers who found these articles interesting may also like to read the following papers found in recent and future issues of our sister publications, Seminars in Thoracic and Cardiovascular Surgery and Operative Techniques in Thoracic and Cardiovascular Surgery!

\section{Acquired: Perioperative Management}

ORIGINAL SUBMISSION: The Effects of Steroids on Coagulation Dysfunction Induced by Cardiopulmonary Bypass: A Steroids in Cardiac Surgery (SIRS) Trial Substudy. Domenico Paparella. Semin Thoracic Surg 2017: In press.

Editorial Commentary: Steroids and Cardiopulmonary Bypass: a Never-ending Story. Thierry Carrel. Semin Thoracic Surg 2017: In press.

ORIGINAL SUBMISSION: Controlled Exponentially Weighted Moving Average Chart in Cardiac Surgery: A Simulation Study Across 9 Italian Cardiac Centers. Marco Moscarelli. Semin Thoracic Surg 2016:253-258.

Editorial Commentary: Statistical Process Control in Cardiac Surgery? Ask Your Doctor. Paul Kurlansky. Semin Thoracic Surg 2016:259-260.

ORIGINAL SUBMISSION: Early Extubation: A Proposed New Metric. Todd C. Crawford. Semin Thoracic Surg 2016:290-299.

Editorial Commentary: Early Extubation: A Proposed New Metric or What Was First: The Egg or the Chicken? Thierry Carrel. Semin Thoracic Surg 2016:300-301. 